\title{
NECESIDADES BÁSICAS \\ Y DERECHOS HUMANOS
}

I

a comisión de derechos humanos de las Naciones Unidas empezó ya en el año
1946 los trabajos preparatorios de los pactos internacionales de los derechos
humanos. En 1954, el texto de los pactos internacionales de derechos políticos
y civiles, así como el de derechos económicos, sociales y culturales, ya eran
objeto de discusión. Pero sólo doce años después, en diciembre de 1966, la Asamblea General de las Naciones Unidas aprobó los dos pactos. Y hubieron de transcurrir aún diez años antes de que entrasen en vigor, en 1976, tras la ratificación por treinta y cinco Estados.

Pero con esto se acaban las correspondencias de la suerte de los dos pactos. El pacto de derechos políticos y civiles ha llegado a ser parte integrante del derecho internacional. En el seno del comité de derechos humanos, se discuten los informes presentados regularmente por los gobiernos de los Estados signatarios. Las resoluciones y recomendaciones del comité gozan de un alto prestigio internacional. Los gobiernos tienen que tomarlas en cuenta; invocar la soberanía nacional o asuntos internos ya no sirve como recurso contra críticas del comité.

Diferentes gobiernos se han visto forzados a autorizar viajes de inspección destinados a aclarar la dudosa situación de los derechos humanos en los respectivos países. En los últimos años, un miembro del comité visitó regularmente Afganistán y el año pasado un grupo de expertos viajó a Cuba. Se recuerdan también las inspecciones en Argentina y Chile. Indudablemente, la situación de los derechos políticos y civiles ha mejorado, y la labor del comité de derechos humanos ha contribuido a este desarrollo positivo, aunque estemos lejos de la realización plena y mundial de estos derechos.

Contrasta con esta imagen positiva, la negligencia con la cual fue tratado el pacto de derechos económicos, sociales y culturales. 
El grupo de expertos gubernamentales nombrado por el Consejo Económico y Social, se ha reunido con poca frecuencia y sus deliberaciones no suscitan la atención pública. Los informes de los gobiernos no han tenido gran valor informativo. Sólo en 1987 se nombró un comité de expertos independientes, comparable en sus competencias y procedimientos con el comité de derechos humanos. Sin embargo, está aún por ver si esta reforma refuerza visiblemente el pacto de derechos económicos, sociales y culturales. ${ }^{1}$

Los resultados discrepantes de los dos pactos requieren una explicación. Los objetivos del pacto de derechos políticos y civiles, caben dentro de una concepción tradicional del derecho constitucional. Tanto para redactar el texto, como para su interpretación y aplicación jurídicas, el comité podía recurrir a la experiencia acumulada en materia de derecho constitucional en muchos Estados signatarios del pacto. Por su parte, el público jurídico observaba las actividades del comité y las comentaba, a veces aprobándolas, a veces criticándolas, pero siempre con simpatía. La existencia de tribunales constitucionales en muchos países, subrayaba la justiciabilidad de los derechos políticos y civiles. $^{2}$

La situación de los derechos económicos y sociales se presenta de otro modo, debido a la innovación jurídica que supone: La legislación tradicional en materia económico-social se refiere a actividades: el ciudadano tiene el derecho de hacer X; está prohibido hacer $\mathrm{Y}$, es obligatorio hacer $\mathrm{Z}$. Los razonamientos subyacentes a estas legislaciones son los siguientes:

1. Tenemos la situación A, la cual queremos que cambie en B. A tal efecto, obligamos a los afectados a hacer $\mathrm{Z}$.

2. Tenemos la situación $C$, la cual queremos conservar; por lo tanto, queda prohibido hacer $Y$.

Otros razonamientos más diferenciados, pretenden surtir efecto, no a través de la creación de obligaciones o prohibiciones, sino de incentivos y desalientos. En estos casos los afectados tienen el derecho de hacer u omitir X, aprovechando las ventajas o soportando las desventajas, según el caso. En todo caso, esta legislación es un medio para alcanzar objetivos socio-económicos. Es evidente que un razonamiento de este tipo está sujeto a muchas imponderabilidades. La historia está llena de ejemplos

${ }^{1}$ Alston, Philipp, «Out of the Abyss: The Challenges confronting the New UN Committee on Economic, Social and Cultural Rights», en Human Rights Quaterly, vol. 9, 1987, págs. 332-381.

${ }^{2}$ Alston, op. cit., pág. 351. 
de consecuencias no planeadas que han impedido la realización de los fines pretendidos. Por esta inseguridad insuperable, resultan interminables las discusiones, conflictos y disputas sobre política económica y social, aun cuando exista consenso sobre los fines. La tentativa, pues, de formular a nivel mundial «derechos económicos y sociales» que deberán formar parte del derecho internacional, sería una tarea imposible, si se incluyeran leyes en el sentido tradicional de la palabra. Consecuentemente, el pacto no intenta precisar las políticas recomendables para la realización de los derechos socio-económicos. Se limita a formular objetivos, dejando sin tratar los medios para alcanzarlos. La formulación del texto no oculta el carácter de compromiso entre ideologías contradictorias. En consecuencia, las interpretaciones del texto se diferencian según la ideología del intérprete.

Esta situación explica el poco interés que el pacto de derechos económicos, sociales y culturales ha suscitado en la comunidad internacional de juristas. Sólo a partir de los últimos años ha surgido un debate científico sobre estos derechos. La extensa documentación que el Human Rights Law Journal publica desde 1980 en su sección Decisions and Reports (Fallos e informes) no incluye hasta ahora ningún caso de litigio por violación de un derecho económico o social.

El pacto internacional de derechos económicos, sociales y culturales, tiene el carácter de un catálogo de objetivos simpáticos, pero difícilmente se lo puede entender como instrumento legal. ${ }^{3}$

${ }^{3}$ La lectura concienzuda de los Limburg Principles on the Implementation of the International Covenant on Economic, Social and Cultural Rights (UN Doc. E/CN.4/1987/17, Annex), que formulan principios de interpretación del pacto, no conduce a otra conclusión: se evita cuidadosamente cualquier alusión directa o indirecta a medidas o políticas específicas que pudieran facilitar (o impedir) la realización de los objetivos del pacto. Sin embargo, el inciso 20 de los Limburg Principles podría -una vez puesto en práctica- revolucionar el rol de las Naciones Unidas discutiendo en un ámbito internacional las políticas socioeconómicas de los países: «20. The appropiarteness of the means to be applied by a particular state shall be determined by that State party, and shall

he subject to review by the United Natiotis and Social Council, with the assistence of ihe Committee.» Pero, los Limburg Principles son el resultado de discusiones de 29 «distinguished experts in international law, convened by the International Commission of Jurists, the Faculty of Law of the University of Limburg (Maastricht, the Netherlantls), and the Urban Morgan Institute for Human Rights, University of Cincinnati (Ohio, USA)». Es decir, se trata de un documento científico, no diplomático. Además, entre los países de origen de tales participantes, que no eran representantes de organismos internacionales o de instituciones patrocinadoras, figuraban sólo dos países del Tercer Mundo: 
El intento de hacer efectivos derechos socioeconómicos a través de disposiciones legales ha fracasado, sobre todo en el Tercer Mundo. O bien las disposiciones legales no han cambiado la realidad socioeconómica caracterizada por un hambre, analfabetismo y una miseria generalizados; o bien una política leninista ha llegado a una distribución más o menos igualitaria de la pobreza, mejorando los niveles de educación y de asistencia sanitaria, pero acompañándola de importantes violaciones de los derechos políticos y pagando el precio de un estancamiento económico generalizado.

Me parece obvio que los derechos humanos tienen que ser contemplados en conjunto: no se puede emprender la tarea de hacer efectivos los derechos socioeconómicos por medios que violan los derechos políticos. ${ }^{4}$

II

La tesis que trato de fundar en estas reflexiones reza: la realización de derechos económicos, sociales y culturales es un proceso social. El Estado no puede dirigir este proceso directamente. Pero el papel del Estado es importantísimo para proporcionar un marco legal, dentro del cual los ciudadanos se esfuercen ellos mismos por realizar sus derechos socioeconómicos.

Es evidente que esta tesis sobrepasa los límites de una interpretación jurídica o filosófica de los derechos humanos. Significa entrar en la polémica científica y política en torno a las estrategias de desarrollo. No se trata de fundamentar o justificar la idea de los derechos humanos en materias socioeconómicas, sino de reflexionar sobre la posibilidad de fertilizar la teoría y la política de desarrollo con la inclusión de los derechos humanos en el discurso sobre el porvenir de la humanidad.

Obviamente, no puedo agotar esta problemática universal en las observaciones modestas que siguen. Me limitaré a delinear brevemente uno de los múltiples problemas que se imponen a

México y Senegal. Todo este contexto justifica un cierto escepticismo en referencia a la eficacia de estos principios en el ámbito de las Naciones Unidas. «The Limburg»

${ }^{4}$ «3. As human rights and fundamental freedoms are indivisible and interdependent, equal attention and urgent consideration should be given to the implementation, promotion and protection of both civil and political, and economic, social and cultural rights.» ibid., pág. 123. 
cualquier investigador de temas de desarrollo: la relación del llamado «sector informal» con el Estado. Este problema puede observarse en todos los países del Tercer Mundo, sin que importe la estrategia de desarrollo seguida por el gobierno respectivo. El director del Programa Mundial del Empleo presenta el asunto como sigue: «Resulta urgente diseñar una política hacia el sector informal. Se estima que más de treinta millones de personas laboran en este sector de la economía, que ha operado como una suerte de seguro de desempleo en casi todos los países de la región. Las políticas hacia el sector informal deberían orientarse a reforzar su capacidad productiva y a superar los obstáculos que representan para el desarrollo del sector algunos aspectos de la legalidad e institucionalidad vigentes». ${ }^{5}$ Es por razones prácticas y de evidencia, por lo que aquí me refiero a un caso específico, basándome en una investigación empírica que Hernando de Soto y sus colaboradores realizaron en Lima y que se publicó bajo el título El otro sendero. La revolución informal en noviembre de 1986. ${ }^{6}$ En diciembre de 1987 apareció la décima edición del libro, elevándose así su tirada a más de sesenta mil ejemplares. Para Perú, un verdadero bestseller.

El libro cuenta la historia de la lucha diaria de cientos de miles, posiblemente de millones de personas en Lima, para satisfacer sus necesidades básicas: vivienda y alimentación. Las actividades económicas parecen, a primera vista, convencionales: negocios de cualquier clase, desde vendedores ambulantes hasta comercio al por mayor, artesanía, pequeña industria, transporte urbano, etc. Esta variedad de ocupaciones indica algo obvio que, sin embargo, a menudo se olvida: la sociedad informal está estratificada en sí misma. No es la masa amorfa del Lumpenproletariat marxiano. La percepción de los asentamientos informales como centros de delincuencia y prostitución, no refleja la realidad social, sino los prejuicios de las clases alta y media hacia los informales. Habrá criminales, mendigos y prostitutas. Pero son grupos minoritarios no representativos para el conjunto social de la informalidad. Más representativos son los oficios de artesanía, comercio, pequeña industria y transporte. Esto indica que el sector mueve capitales apreciables, aunque parezcan muy modestos en cada caso individual. Lo sorprendente que explica la

${ }^{5}$ Tokman, Víctor, «Ajuste estructural. La deuda social de América Latina», en El País, 10 de abril de 1989, pág. 62.

${ }^{6}$ De Soto, Hernando, en colaboración con Enrique Ghersi, Mario Ghibellini y el Instituto Libertad y Democracia (ILD), El otro sendero. La revolución informal. Prólogo de Mario Vargas Llosa, Lima/ Bogotá, 1986. 
discusión en el presente contexto es que todas estas actividades son ilegales. Llamarlos «informales» es un eufemismo basado en el hecho de que la multiplicidad de actos ilegales trae consigo la imposibilidad de imponer la ley. Por esta razón, meramente práctica, la ilegalidad se convierte en extralegalidad. En legalidad no puede convertirse. Los costos de la legalidad son prohibitivos: colaboradores de Hernando de Soto simularon la constitución regular de «un pequeño taller de confecciones de prendas de vestir», haciendo directamente los trámites respectivos. ${ }^{7}$ «Los resultados arrojaron que una persona modesta debía tramitar por 289 días antes de obtener los once requisitos previos a la instalación de una pequeña industria». ${ }^{8}$ "Se incurre en un costo por trámites de 194,4 dólares. Además la espera de casi diez meses para iniciar las actividades produce una pérdida de utilidades netas de 1.036,6 dólares; de manera que el costo total de acceso a la pequeña industria es de 1.231 dólares, equivalente a 32 veces el sueldo mínimo vital». ${ }^{9}$

La legalidad no está al alcance de los pobres. Y este hecho no sólo se refiere a la actividad económica, sino también a la vivienda. Al comienzo de los años 80, aproximadamente la mitad de las viviendas de Lima pertenecían a asentamientos informales; «para fines de 1985, por cada 100 casas levantadas ese año en Lima, los informales eran propietarios de 69 y los formales sólo de $31 .{ }^{10}$

La conversión de la ilegalidad en extralegalidad no da seguridad a los afectados. En la historia contemporánea de Lima, abundan tentativas frustradas de imponer el orden legal a la informalidad de la vida social. Las acciones policiales a fin de limpiar las calles de la capital de los vendedores ambulantes, para impedir la toma violenta de terrenos sin edificar para construir viviendas, etc., siempre han fracasado. Pero constituyen una amenaza constante para los hombres y mujeres que no ven -y de hecho no tienen- ninguna otra alternativa para ganarse la vida. Y es esta amenaza la que caracteriza la imagen del Estado y de sus agentes. Se presentan como un poder incalculable del que uno debe captarse las simpatías por el medio de pagos, también ilegales.

Pienso que toda esta problemática se encuentra en el centro mismo de nuestro tema de «necesidades básicas y derechos humanos».

${ }^{7}$ Íbid., pág. 173.

${ }^{8}$ Íbid., pág. 174.

${ }^{9}$ Loc. cit.

${ }^{10}$ Íbid., pág. 59. 
Los informales se esfuerzan enormemente por satisfacer sus necesidades más fundamentales: alimentación y vivienda. Y lo hacen por iniciativa propia y sin esperar que alguna autoridad benévola o una agencia internacional les ayude con propinas o limosnas. Las condiciones que incitan a estos esfuerzos son sumamente difíciles. La dificultad más importante es la marginalidad jurídica. Ya no se puede hablar de marginalidad social, primero, porque no se puede calificar de fenómeno marginal a un sector que posiblemente comprende la mayoría de la población; segundo, porque las interacciones y penetraciones mutuas de los sectores formales e informales son tan intensas, que una división es imposible y carecería de sentido. ${ }^{11}$ Pero persiste la marginalidad jurídica. La población activa en el sector informal no goza de la función protectora del derecho formal, ni en lo que se refiere a las interacciones de los informales entre sí, ni con respecto a las transacciones con el sector formal, o a los trámites en la burocracia estatal.

Desde el punto de visa de la teoría del derecho y del Estado, los informales actúan en un espacio sin orden jurídico. Se encuentran en una situación de tolerancia precaria, intrínsecamente ilegal. Piensan poder mantener esta situación sólo por pagos «útiles», que tienen más el carácter de tributos feudales que de soborno, por no hablar de impuestos legales.

Ello se debe primordialmente a que no tienen ninguna propiedad legal. No disponen de nada más que de derechos de usufructo, revocables en cualquier momento, del terreno donde han construido su casita o choza, del puesto de venta en alguna calle, del taller donde trabajan en su oficio, o de la ruta en la cual desempeñan el transporte urbano con sus microbuses o furgonetas.

${ }^{11}$ Esta afirmación no supone que no exista marginalidad social. Pero niega la identificación de los informales con los marginales. «La sociedad formal considera al individuo o grupo de pobres o marginales como 'incapaces' de integrarse a la sociedad formal en la cual las personas supuestamente tienen posibilidades de triunfar 'si se esfuerzan y trabajan'. Al culpar de esta manera al propio marginalizado de su marginación, miseria y pobreza, la sociedad, a través de un discurso ideologizante, logra hacerle creer que es realmente incapaz y culpable de su condición: incapaz de dar pasos hacia soluciones de los problemas con su fuerza y sus propios medios.» Glauser, Benno, «Elementos de la cultura como respuesta a la vida en barrios marginales de Asunción», en Ifda dossier, núm. 68, november/december 1988, págs. 17-18. El marginado ha perdido la confianza en sí mismo, se identifica con los prejuicios de la sociedad formal. El trabajador informal sabe muy bien diferenciar entre los obstáculos que impone la estructura social y política a su porvenir, y la capacidad y el esfuerzo de los que él mismo dispone para enfrentarse a estos obstáculos. 
En las interacciones entre sí, se encuentran en una situación pre-estatal, en una situación de estado natural, para decirlo en términos clásicos de la teoría política. Existen normas sociales, pero no existe autoridad central que imponga estas normas en caso necesario.

Las transacciones comerciales del sector informal no se diferencian fundamentalmente de las que realiza el sector formal: se compra y se vende, se reciben créditos y se amortizan, se conciertan contratos entre abastecedores y clientes, etc. A falta de un derecho formal, estas transacciones se rigen por un conjunto de normas que Hernando de Soto llama la «normatividad extralegal». ${ }^{12}$ Está basada exclusivamente en el acatamiento voluntario de los deberes y derechos mutuos de las partes interesadas. Solamente en casos excepcionales, cuando los intereses de una colectividad se ven afectados, puede hacerse presión social contra el infractor de un contrato. El hecho de que la protección jurídica formal resulte inasequible, presenta el más grave obstáculo para el aprovechamiento óptimo de los recursos de los informales. Hernando de Soto enumera tres deficiencias jurídicas al respecto: falta de la garantía de la propiedad; falta de un derecho de contratos realizable, que permitiría transacciones con personas desconocidas; y falta de un derecho de responsabilidad extracontractual. También el sector formal sufre, por lo menos parcialmente, estas deficiencias jurídicas; pero éste sabe compensar sus consecuencias perjudiciales recurriendo a regulaciones administrativas por parte de órganos estatales. Veremos este punto más adelante.

\section{III}

Resumiendo lo expuesto hasta aquí, podemos decir: un sinnúmero de personas de los estratos inferiores de la sociedad, realiza diariamente esfuerzos extremos para ganarse la vida y asegurarse un techo para dormir. Lo hace al margen o fuera del orden legal existente. En sustitución de éste desarrolla un sistema de normatividad extralegal, con el cual intenta compensar la falta de derecho formal justiciable, sin llegar a conseguirlo plenamente.

Una tal normatividad pre-estatal y exclusivamente social sin poder central, requiere para su funcionamiento un alto grado de

${ }^{12}$ De Soto, op. cit., págs. 23, 71, 73 e.a. 
aceptación y legitimación. Cualquiera que se sienta perjudicado por alguna norma, puede sustraerse de la misma sin que existan sanciones efectivas.

Podemos conjeturar, pues, que la normatividad extralegal cumple con el requisito de justicia política que formula Otfried Höffe: La coexistencia en libertad distributivamente ventajosa (Die distributiv vorteilhafte Freiheitskoexistenz)». ${ }^{13}$ ¿Qué quiere decir eso? Aceptar normas significa eo ipso aceptar límites de la libertad. Estos límites requieren justificación y legitimación. Y éstas se producen por el hecho que la coexistencia sea «distributivamente ventajosa», es decir, ventajosa para cada uno individualmente, no sólo para la colectividad. Es importante que quede claro que se trata de la distribución primitiva por medio del trueque justo, y no de la redistribución de ganancias antes distribuidas.

El dilema de tal normatividad sin poder central, consiste en la imposibilidad de resolver el problema del polizón (free rider). Es imposible impedir que algunos se aprovechen de las renuncias de los demás a ciertas acciones, es decir, que se aprovechen de las restricciones voluntarias de la libertad ajena, sin que ellos mismos se dejan regir por estas normas. Volveremos a este problema enseguida.

El medio más importante del trueque distributivamente ventajoso, es el contrato que celebran dos o más personas para provecho de cada una de las partes contratantes. E1 contrato también es -y con esto entramos en la economía- un medio para disponer de recursos. Solamente puede disponer de recursos, quien cuenta con propiedad, sea propiedad propia, sea propiedad ajena de la cual está autorizado a disponer por vía de contrato. El contrato es, por su naturaleza, una decisión que compromete a las partes para el futuro. Pero el contrato como medio de auto-organización social, necesita requisitos indispensables, los cuales no pueden realizar las partes contratantes. Estos requisitos son:

Primero.- La garantía de la propiedad que permita al hombre disponer de recursos.

Segundo.- La existencia de un poder central que imponga el contrato en caso de conflicto.

Tercero.- Seguridad frente a posibles consecuencias de actividades contractuales socialmente nocivas, es decir, un derecho

${ }^{13}$ Höffe, Otfried, Politische Gerechtigkeit. Grundlegung einer kritischen Theorie von Recht und Staat, Frankfurt /M, 1987, pág. 382. 
de responsabilidad extracontractual. Estos requisitos indispensables tiene que proveerlos el Estado. Un Estado que niega a sus ciudadanos estas condiciones para sus actividades socio-económicas, dificulta el abastecimiento de las necesidades básicas. Me parece que esto constituye una violación de derechos humanos.

Es sorprendente que, en estas reflexiones sobre la satisfacción de necesidades básicas de los más pobres en el Tercer Mundo, se hable tanto de la garantía del derecho a la propiedad. El asunto me parece tan importante que me permito una pequeña disgresión.

El discurso europeo sobre la función social de la propiedad, se dedica primordialmente a discutir cómo se puede proteger a los pobres contra la dominación por parte de los ricos. ${ }^{14}$ La mayoría de los países del Tercer Mundo ha imitado esta actitud, por lo menos en las palabras. Y es un punto de vista muy cierto. Es preciso proteger al peón de una hacienda azucarera de las Filipinas o del nordeste del Brasil, contra el poder arbitrario del latifundista respectivo. Esta protección es desesperadamente deficiente en los países mencionados y en muchos otros. Pero, ¿constituye la posibilidad de abuso por parte de la gran propiedad una razón suficiente para descalificar absolutamente al concepto de propiedad? La declaración universal de derechos humanos de 1948 dice en su artículo 17: «Toda persona tiene derecho a la propiedad, individual y colectivamente. Nadie será privado arbitrariamente de su propiedad.» Es correcto objetar que el pacto internacional de derechos económicos, sociales y culturales de 1966, no menciona el derecho a la propiedad. Pero esta falta se explica por la fuerte presencia de países socialistas en las Naciones Unidas.

Es evidente que se necesita una reforma agraria en las Filipinas y en Brasil y en otros países. Pero, ¿qué sistema de tenencia de tierra reemplazará al latifundismo? Experiencias poco dignas de imitación han podido verse en varios países, donde reformas agrarias sustituyeron a un latifundista todopoderoso por un administrador igualmente todopoderoso, por lo menos en su trato con los peones. ${ }^{15}$ Una reforma agraria razonable debe

${ }^{14}$ Véase, por ejemplo, Rittstieg, Helmut, Eigentum als Verfaissungsproblem. Zu Geschichte und Gegenwart des bürgerliceh Verfassungsstaats, Darmstadt, 1976. Schwartländer, Johannes y Dietmar Willoweit (eds.), Das Recht des Menschen auf Eigentum, Kehl y Strasbourg, 1983 (Tübinger Universitätsschriften Forschungsprojekt Menschenrechte, vol. 3).

${ }^{15}$ Un caso ejemplar se podía observar en el Perú, cuando el gobierno militar del general Juan Velasco Alvarado realizó una reforma agraria bastant 
en alguna forma de propiedad que incluya para los favorecidos la libertad de disposición.

Sabemos por múltiples experiencias, que la mera expropiación no resuelve ningún problema pero plantea muchas dificultades nuevas. La reforma agraria es, indudablemente, un requisito indispensable para el desarrollo rural en muchos países del Tercer Mundo; solamente combinándola con todo un paquete de medidas acompañantes, que no puedo detallar aquí, se convierte en un requisito suficiente. ${ }^{16}$

Volvamos a las reflexiones teóricas sobre la propiedad. La preocupación dominante por la gran propiedad, que en el Tercer Mundo es a menudo de origen colonial y características feudales, ha oscurecido una relación elemental: la relación entre propiedad y trabajo. Cuando se introdujo la libertad industrial en la segunda mitad del siglo XVIII, esta relación quedaba bien clara. En el decreto del ministro Turgot de 1776 sobre la libertad industrial en Francia, se habla de las necesidades que el hombre tiene que satisfacer por el trabajo, y se afirma que «el derecho al trabajo es la propiedad santa e inalienable del hombre. Acabemos por esto con toda institución que impida a los necesitados vivir de su trabajo». ${ }^{17} \mathrm{Y}$, otra vez, tenemos que revisar la comprensión europea del derecho a trabajar antes de discutir sobre el contenido que tenga para el Tercer Mundo. El derecho a trabajar se convertía en la discusión europea en un «derecho al trabajo», entiéndase por «derecho al trabajo», el derecho a una plaza de plantilla como obrero dependiente. En este sentido, el derecho al trabajo se encuentra en algunas constituciones y figura también en el pacto internacional de derechos económicos, sociales y culturales. No voy a entrar en la polémica sobre un tal

radical en 1969. Véase, por ejemplo, Bourque, Susan C. y David Scott Palmer. «Transforming the Rural Sector: Government Policy and Peasant Response», en Lowenthal, Abraham F. (ed.), The Peruvian Experiment: Continuity and Change under Military Rule, Princeton N. J., 1975, págs. 179-219. Hardin, Colin, «Land Reform and Social Conflict in Peru», en Lowenthal (ed.), op. cit., págs. 220-253.

${ }^{16}$ Con mucha razón, la reforma agraria es un tema clave del debate sobre el desarrollo desde mucho tiempo. Me limito a mencionar dos títulos ya clásicos: Delgado, Óscar (ed.), Reformas agrarias en la América Latina, México DF. y Buenos Aires, 1965. Warriner, Doreen, Land Reform in Principle and Practice, Oxford, 1969.

${ }^{17}$ Ramm, Thilo, «Das Recht auf Arbeit und die Gesellschaftsordnung», en Ryffel, Hans y Johannes Schwartländer (eds.), Das Recht des Menschen auf Arbeit, Kehl y Strasbourg, 1983 (Tübinger Universitätsschriften Forschungsprojekt Menschenrechte, vol. 4), pág. 66. 
«derecho al trabajo» como derecho constitucional en Europa. Pero insisto en que, refiriéndose al Tercer Mundo, un tal derecho queda en plano de mera retórica, sin consecuencias positivas algunas.

Típico, en este sentido, es el artículo 14 de la declaración americana de los derechos y deberes del hombre: «Toda persona tiene derecho al trabajo en condiciones dignas y a seguir libremente su vocación, en cuanto lo permitan las oportunidades existentes de empleo.

Toda persona que trabaje tiene derecho de recibir una remuneración que, en relación con su capacidad y destreza le asegure una vida conveniente para sí misma y su familia.»

Cambiando la sintaxis de la primera frase, resulta lo siguiente: Quien tiene empleo, tiene derecho a condiciones dignas en su puesto de trabajo. La realidad socioeconómica, caracterizada por una mayoría de personas fuera de empleos formales, queda completamente excluida de este pensamiento jurídico. Y esta negligencia se convierte en puro cinismo, al compararlo con el artículo 37: «Toda persona tiene el deber de trabajar, dentro de su capacidad y posibilidades, a fin de obtener los recursos para su subsistencia o en beneficio de la comunidad.»

No es necesario ser marxista para llegar a la conclusión de que los derechos humanos son un pensamiento de ricos para ricos, teniendo en cuenta que en el Tercer Mundo los obreros con empleo fijo forman parte de las clases privilegiadas.

Entonces, ¿qué significa «el derecho a trabajar» en el contexto de una política de satisfacción de necesidades básicas? Tenemos que renunciar a formular un derecho justiciable directamente, porque hoy en día y durante un largo tiempo, es imposible asegurar a los hombres del Tercer Mundo puestos de trabajo mediante medidas administrativas. Pero lo que hay que reivindicar es un orden político y jurídico que no discrimine a las personas que buscan posibilidades de trabajo para ganarse la vida, sino que las fomente.

Durante un tiempo incalculable, un sinnúmero de personas, la mayoría en muchos países, seguirá esforzándose por sobrevivir en el sector informal. El trabajador eufemísticamente llamado «Independiente» no sólo no goza de ninguna protección social por parte del Estado, sino que también ve obstaculizados sus esfuerzos por parte de una administración pública que quiere seguir los modelos de países industrializados, pero ni siquiera regula eficientemente el sector formal. Para el orden jurídico y administrativo, el sector informal constituye una economía sumergida, a lo sumo tolerada. La regulación del sector formal no 
funciona por leyes generales vigentes para todos los ciudadanos, sino por disposiciones administrativas específicas a fin de favorecer grupos o personas, desfavoreciendo intrínseca o abiertamente a otros. Cualquier actividad económica adquiere el carácter de un privilegio otorgado por la autoridad del Estado. Y el proceso político degenera en la lucha por el acceso al poder para fomentar intereses particulares en detrimento de los demás. ${ }^{18}$ El sector formal goza de estos privilegios que le protegen de la competencia de otros sectores y se contenta con las limitaciones del desarrollo que esta actitud trae consigo. Los informales no quieren favores, sino condiciones legales de igualdad, y esto les es negado.

\section{IV}

Después de tanta polémica, es preciso reflexionar sobre el concepto de necesidades básicas y su relación con los derechos humanos. La preocupación por las necesidades básicas resulta del descontento creciente, tanto con los indicadores convencionales de medición de desarrollo como con los resultados desesperados de la política de desarrollo seguida durante décadas. Para nuestro contexto, sólo el segundo aspecto tiene importancia. Se trata de proyectar una nueva política de desarrollo apta para el mejoramiento encauzado de las condiciones de vida de los estratos más pobres de las sociedades respectivas.

¿Qué significa «mejorar las condiciones de vida mediante la satisfacción de necesidades básicas?» Cuando, a causa de una catástrofe natural, faltan alimentos y la muerte de muchas personas está a la vista, la solución del problema es teóricamente fácil: hay que proveer a la gente de alimentos para salvar vidas. Y felizmente, conocemos bastantes ejemplos de ayuda rápida y eficiente. Pero este caso extremo sirve poco de orientación, porque reduce el problema a una sola dimensión. Siendo relativamente exitosa una acción de ayuda inmediata en una situación de emergencia, pronto llega el momento en el que el abastecimiento de alimentos ya no basta para satisfacer las necesidades básicas.

Se ha escrito mucho últimamente sobre las consecuencias nocivas de una prolongada ayuda alimenticia porque perjudica la producción agraria interna, empeorando aún más el nivel de

${ }^{18}$ De Soto, op. cit., págs. 239 y sigs. 
vida de los campesinos. Pero en este debate han prevalecido los argumentos económicos, aunque los puntos no-económicos tengan por lo menos la misma importancia. Un slogan frecuentemente usado -y cierto a mi parecer- en el debate sobre ayuda al desarrollo, habla de la «ayuda a la auto-ayuda». Este slogan indica que no sólo se trata de mejorar situaciones económicas, sino que el mejoramiento de las condiciones de vida tiene que ser a su vez consecuencia del crecimiento de la capacidad productora de los afectados. Para lograr esto se necesita más que contribuciones materiales. El crecimiento de la capacidad productora resulta de la intensificación del control y del uso de los recursos disponibles, de procesos de aprendizaje que incluyen cambios de las interacciones, resultando eventualmente invenciones sociales. En una palabra: la estrategia de satisfacción de necesidades básicas no consiste en técnicas de crecimiento económico, sino en esfuerzos para dinamizar una sociedad desde los estratos más modestos.

Con esto, las estrategias de las necesidades básicas caen en un dilema: si se logra el propósito de dinamizar la sociedad, resultarán inevitablemente conflictos sociales y políticos. Los gobiernos, para evitar estos conflictos, prefieren ofrecer proyectos de necesidades básicas en las formas tradicionales de instituciones de servicios, administradas por funcionarios. Educación formal y asistencia sanitaria figuran por esto tan alto en las listas de prioridades de gobiernos autoritarios. Los receptores han de quedar en condición de clientes dependientes del big brother. El crecimiento de la capacidad productora propia de la gente es visto como inoportuno. Consecuentemente, la planificación del desarrollo consiste hasta hoy en una planificación central, trazada por «expertos altamente cualificados», que tienen inmensas dificultades en integrar a los afectados en los procesos de elaboración y ejecución de planes. Los llamados «favorecidos» persisten en una actitud de consumidores, lo que es contraproducente bajo el aspecto de la estrategia de necesidades básicas esbozada.

En otras palabras: las estrategias de satisfacción de necesidades básicas, aptas para alcanzar el fin de crecimiento de la capacidad productora, ampliarán el espacio de acción autónoma de los favorecidos ante otros agentes, incluido el Estado. Autonomía quiere decir: enumerar por derecho propio las múltiples alternativas de acción, seleccionar las más adecuadas, disponerlas según orden de prioridades y llevarlas a cabo. Además, por derecho propio, organizar y estipular las relaciones materiales y no-materiales con el ambiente social.

Con este argumento volvemos a los derechos humanos. El 
inciso uno del artículo primero, común a los dos pactos internacionales de derechos humanos dice: «Todos los pueblos tienen el derecho de libre determinación. En virtud de este derecho establecen libremente su condición política y proveen asimismo a su desarrollo económico, social y cultural.» Los gobiernos del Tercer Mundo suelen interpretar este texto como prohibición implícita de la democracia, en particular del colonialismo. Esta interpretación es justa pero incompleta. El inciso no habla de gobiernos sino de pueblos. El texto reclama categóricamente la democracia, siendo esta forma de gobierno la única legítima a la luz de los derechos humanos. No es necesario identificar esta autodeterminación democrática con la democracia del Atlántico Norte. Pero no es admisible que los gobiernos tracen planes de desarrollo, con o sin participación extranjera, y traten de realizar estos planes en última instancia con medidas violentas, sin enterarse de los pareceres posiblemente bien distintos de la población.

Informa el africanista alemán Franz Ansprenger, de que en Tanzania, después de la independencia, el gobierno intentó por todos los medios destruir las cooperativas cafeteras de mayor éxito, por no ser suficientemente socialistas. ${ }^{19}$ Esta actitud -y existe un sinnúmero de ejemplos parecidos -no sólo es una tontería en términos económicos, sino que constituye un ataque frontal contra los derechos humanos y la satisfacción de necesidades básicas.

Los gobiernos del Tercer Mundo, temiendo perder el control de sus sociedades, han optado por una política mercantilista, que no se basa en un sistema de derechos iguales para todos los ciudadanos, sino que desea dominar la sociedad otorgando o denegando privilegios y protección a grupos específicos. De esta manera, se excluye del sistema legal a un creciente sector de la sociedad, lo que pone en peligro no sólo la estabilidad de los regímenes, sino el desarrollo mismo de las sociedades. Esta crítica acierta igualmente en los gobiernos de derecha y de izquierda:

«... entre el mercantilismo de derecha y el de izquierda existen, por supuesto, diferencias: unos gobernarán para servir a la inversión extranjera o ayudar a los empresarios nacionales, y otros para redistribuir el bienestar hacia los más necesitados. Pero en todos los casos lo harán con malas leyes, favoreciendo explícitamente a algunos y desfavoreciendo a otros. Entonces,

${ }^{19}$ Ansprenger, Franz, «Versagen und Leistung des unabhängigen Afrika», en Aus Politik und Zeitgeschichte-Beilage zur Wochenzeitung das Parlament, num. B 29/30-86, 19 de julio 1986, pág. 10. 
aunque sus objetivos parezcan distintos, lo que resulta es que en el Perú se pierde o se gana por vía de la decisión política. Existen seguramente muchas diferencias entre un zorro y un lobo, pero desde el punto de vista de un conejo son más relevantes sus similitudes.»

«Hoy en día, izquierda y derecha coinciden en ver la informalidad como problema. Ninguna parece haberse dado cuenta de las soluciones que ese mismo problema ofrece; es decir, la forma de utilizar la energía inherente al fenómeno para crear riqueza y un orden distinto. Quizás sea porque, como buenos mercantilistas, la posibilidad de convertir un problema en solución les huele a alquimia, o tal vez porque se oponen a la iniciativa privada de origen popular. Como buenos mercantilistas, coinciden en sentirse seguros sólo si las respuestas son dictadas por una autoridad superior dentro del orden centralista». ${ }^{20}$

Los gobiernos centralistas del Tercer Mundo, sean democráticos o dictatoriales, están en crisis. No tienen la capacidad de satisfacer las necesidades básicas de sus pueblos; $\mathrm{y}$, al mismo tiempo, intentan conservar estructuras jurídicas y administrativas que obstaculizan la satisfacción de necesidades por parte de los necesitados mismos. Y esto constituye una violación de derechos humanos.

${ }^{20}$ De Soto, op. cit., pág. 292. 